\title{
Cultivation Strategies for Scientific Research and Innovation Ability of College Students Majoring in Sports
}

\author{
https://doi.org/10.3991/ijet.v16i06.21093 \\ Min Tang ${ }^{(凶)}$, Dancheng Wei \\ Suihua University, Suihua, China \\ gwz102424@163.com
}

\begin{abstract}
College students majoring in sports form the talent base for sports science. Their scientific research and innovation (SRI) ability directly bears on the level of sports science in future. In this paper, a questionnaire survey on the status quo of SRI ability cultivation for sports majors is carried out among postgraduate students and some teachers of sports department in five colleges of southwestern China's Sichuan Province. The survey paints a grim picture on the SRI ability of sports majors: the students are relatively weak in SRI ability; the teachers have an average SRI ability, and pay insufficient efforts in instructing or cultivating the students' SRI ability; the schools fail to pay enough attention to SRI ability cultivation of sports majors, not to mention creating favorable SRI conditions or environment for them. To solve these problems, the cultivation strategies for SRI ability of sports majors were designed in six aspects, namely, interest development, faculty building, and infrastructure construction. The research results provide new theoretical evidence to SRI ability cultivation of sports majors, and an important reference for promoting their SRI ability.
\end{abstract}

Keywords - Sports majors, scientific research and innovation (SRI) ability, status quo analysis, cultivation strategies

\section{Introduction}

Although sports science has developed into an independent discipline in China, the overall SRI ability of the discipline is weak due to its late start and unsubstantial foundation. College sports majors are the main force for the future of sports science, and their SRI ability directly determines the future development level of sports science in China, therefore, it is of great importance to study the cultivation of the SRI ability of sports majors.

Foreign research on SRI ability cultivation started earlier than China, for example, the United States opened the curtain on innovation education as early as 1935-1950 [1]. By reviewing foreign studies concerning innovation education, it's found that the development of innovation education has gone through three stages: innovation ability research, innovation education research, and innovation education application [2]. 
Scholars in the field have mainly focused on the cultivation methods and content systems of innovation ability [3]. Now, many countries regard SRI ability as an indispensable part of their education systems. For instance, in the United States, the education of each level has a respective student SRI ability cultivation system [4].

In contrast, China's innovation ability cultivation didn't see major changes until 1980. After 1990, the Chinese society began to show interests in innovation, and schools started to conduct research on innovation ability cultivation, and these domestic research results mainly talk about the status quo of the SRI ability, the influencing factors of SRI ability cultivation, and the ways of SRI ability cultivation [5]. After reviewing relevant domestic research, it's found that there's few studies concerning the cultivation of sports majors' SRI ability, and the existing literatures mostly focus on a single aspect of scientific research ability or innovation ability [6].

In view of these situations, first, this paper plotted a sports SRI ability structure diagram and selected several sports postgraduates and teachers from 5 colleges in $\mathrm{Si}$ chuan Province as the research objects to investigate the status quo of the SRI ability cultivation of sports majors; then based on the obtained survey results, this paper summarized problems in the SRI ability cultivation of Chinses sports majors, and then researched the strategies for solving the said problems from six aspects of interest development, faculty building, and infrastructure construction, etc.

\section{Sports SRI Ability}

\subsection{Sports SRI ability and its influencing factors}

Sports SRI [7] refers to the original scientific exploration activities of research subjects using various scientific research resources to explore, reveal, and predict the nature, laws and development trends of the relationship between human and sports and obtain research outcomes with certain values. And the sports SRI ability is the research subjects' comprehensive strength with professional advantages and innovative characteristics in the above-mentioned activities. SRI ability is a complex system, and its influencing factors [8] include human factors, material factors, organizational factors, political factors, environmental factors, and knowledge factors, etc., shown as Figure 1.

Human factor: Human resource is a key factor determining the success of SRI. Without researchers, there's no scientific innovation at all. Besides guaranteeing the numbers, a research team should have senior researchers and a good researcher age structure.

Material factor: Materials are the basic guarantee of SRI. First, scientific innovation is inseparable from the achievements of predecessors, and it requires a large amount of book information; research shows that, the richness of book information has a direct impact on SRI. Second, SRI needs laboratories and various equipment; advanced laboratories and equipment are the important material basis for SRI. Finally, SRI requires research funds; sufficient research funds are not only a prerequisite to 
ensure the material foundation of SRI, but also an important impetus to encourage researchers to engage in SRI activities.

Organizational factor: System theory points out that the whole is greater than the sum of its parts. With the deepening of scientific research, the research tasks cannot be completed by one person, but requires the joint efforts of researchers from different fields. An efficient, stable, scientific and reasonable organization can gather the research resources and give full play to the advantages of various disciplines, so that new research outcomes could be created continuously.

Policy factor: Correct and scientific policies can correctly handle the internal and external relationships in research activities and improve the efficiency of research works, so that the SRI activities could be carried out healthily and continuously.

Environmental factor: A free and innovative academic atmosphere is a basic condition of SRI. The process of SRI is often accompanied by fallacies and it often requires tolerance from people and society. The academic atmosphere mentioned in this paper mainly refers to an environment which can encourage students to express their academic views and communicate with people. In addition, a good organizational culture can also promote the efficiency of collaboration between researchers and improve their SRI ability.

Knowledge factor: Knowledge is the basic condition and social foundation of SRI. The cultivation of SRI ability is inseparable from the mastery and application of knowledge, and knowledge often acts on SRI in the form of information; therefore, good information exchange and communication platforms should be created for researchers, so that knowledge innovation and scientific research innovation could be promoted through communication.

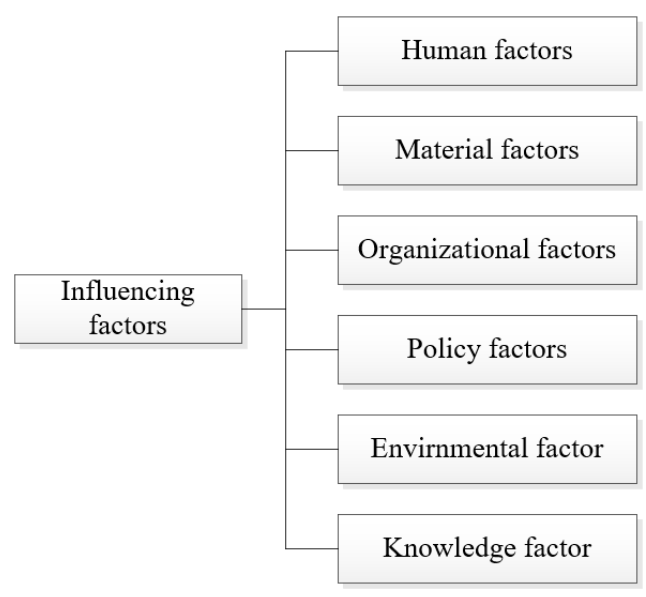

Fig. 1. Factors affecting the ability of sports SRI

\subsection{Elements in sports SRI ability}

The level of sports SRI ability directly determines the success of SRI activities. As mentioned above, SRI ability is a complex system consisting of multiple elements and 
only by thoroughly understanding these elements can we manage the cultivation of sports SRI ability in a targeted manner, and thereby further improving sports majors' SRI ability. Figure 2 gives a diagram of the sports SRI ability structure [9].

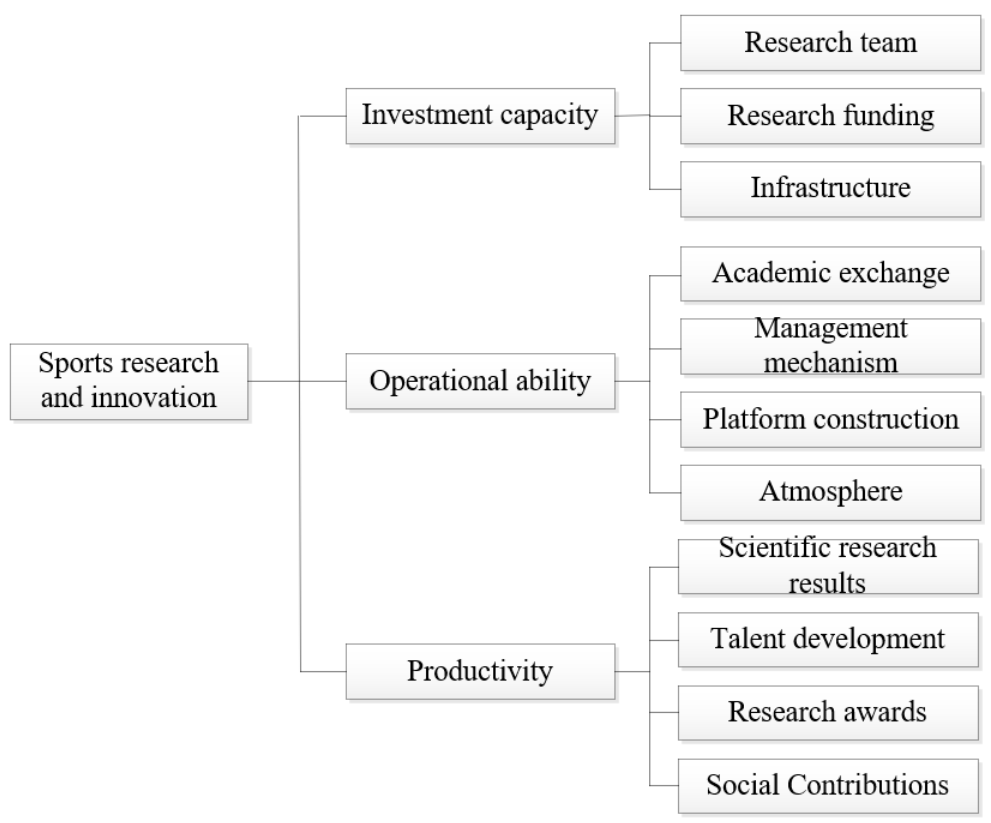

Fig. 2. Structure of sports SRI ability

\section{Status Quo of Sports Majors' SRI Ability and the Cultivation Strategies}

\subsection{Questionnaire survey on the status quo of sports majors' SRI ability}

To figure out the status quo of sports majors' SRI ability, our research team designed Questionnaires on College Students' SRI Ability Cultivation [10] for students and teachers. Sports major postgraduates and teachers from 5 colleges in Sichuan province were selected as research objects. In the survey, a total of 30 teacher questionnaires were issued, 28 valid teacher questionnaires were returned, the valid questionnaire ratio was $93.3 \%$; at the same time, a total of 175 student questionnaires were issued, 150 valid student questionnaires were returned, and the valid questionnaire ratio was $85.7 \%$.

\section{Student SRI achievements}

The number of papers published is an important measure for one's SRI ability [11]. Table 1 shows the survey results of student paper publication and the level of the journals. According to the table, the number of students who published 2 papers ac- 
counted for $80 \%$ of the total number of students, the number of students who published 3 or more than 3 papers accounted for $20 \%$. This is because the colleges have requirements on the number of published papers upon college student graduation, although it seems like a mandatory measure, it is also an important means to promote students' SRI ability. However, the statistics show that more than $95 \%$ of the papers were published by normal level journals, this is because these journals generally do not have high requirements for the quality of papers and the cost is relatively low; as a result, in order to meet the graduation requirements or scholarship application requirements, most students would choose these normal-level and low-cost journals to publish their papers.

Table 1. Statistics of student paper publication and level of journals

\begin{tabular}{|l|c|c|c|c|}
\hline Number of papers published & $\mathbf{2}$ & $\mathbf{3}$ & $\mathbf{4}$ & $\geq \mathbf{5}$ \\
\hline Number of students & 140 & 20 & 10 & 5 \\
(proportion) & $80 \%$ & $11.4 \%$ & $5.7 \%$ & $2.9 \%$ \\
\hline Level of journals & SCI/EI/STP & CSSCI Chinese core & Core journal & General journal \\
\hline Number of students & 0 & 1 & 5 & 169 \\
(proportion) & $0 \%$ & $0.57 \%$ & $2.86 \%$ & $96.57 \%$ \\
\hline
\end{tabular}

In addition, survey results show that the number of students with granted patent is 0 , only $6 \%$ of students have ever participated in research programs, even for those who have, their works are only less-essential jobs, which is not that that helpful for the promotion of their SRI ability.

\section{Students' satisfaction with teachers}

Teachers' instruction methods directly determine students' learning ability and results [12]. Table 2 shows the statistics of student-teacher communication frequency and effective time of each communication. One thing should be noted here is that the communication frequency and time in the survey refer to the effective academic exchange between students and teachers outside the class, it can be seen from the table that, for more than half of the students, the time interval of each communication is relatively long, and $3.43 \%$ of students rarely communicate with teachers. This situation indicates that, the academic atmosphere of sports major is not ideal, which is not conducive to the cultivation of sports majors' SRI ability. Communication time is the basic guarantee for the academic exchange between students and teachers. According to the table, each communication time is relatively long, the communication time of $66 \%$ of students is between 60 and 120 minutes, however, when the long-time interval is taken into consideration, the communication seems far from enough. 
Table 2. Statistics of student-teacher communication frequency and effective time of each communication

\begin{tabular}{|l|c|c|c|c|}
\hline Communication frequency & Once a week & $\begin{array}{c}\text { Once every two or } \\
\text { three weeks }\end{array}$ & $\begin{array}{c}\text { Once every four } \\
\text { weeks }\end{array}$ & Seldom \\
\hline $\begin{array}{l}\text { Number of students } \\
\text { (proportion) }\end{array}$ & 18 & 48 & 103 & 6 \\
\hline Communication time & $30.27 \%$ & $27.43 \%$ & $58.87 \%$ & $3.43 \%$ \\
\hline $\begin{array}{l}\text { Number of students } \\
\text { (proportion) }\end{array}$ & 16 & $30-60 \mathrm{~min}$ & $60-90 \mathrm{~min}$ & $90-120 \mathrm{~min}$ \\
\hline
\end{tabular}

Figure 3 shows the statistics on whether the students think the teachers have taken the SRI ability as the primary cultivation goal, and the results tell us although more than $55 \%$ of students think that the teachers do have taken SRI ability as the primary cultivation goal, still $15.5 \%$ and $2.3 \%$ of them are not sure about it or they disagree, this result indicates that, some students are unclear about the goal and meaning of SRI ability cultivation.

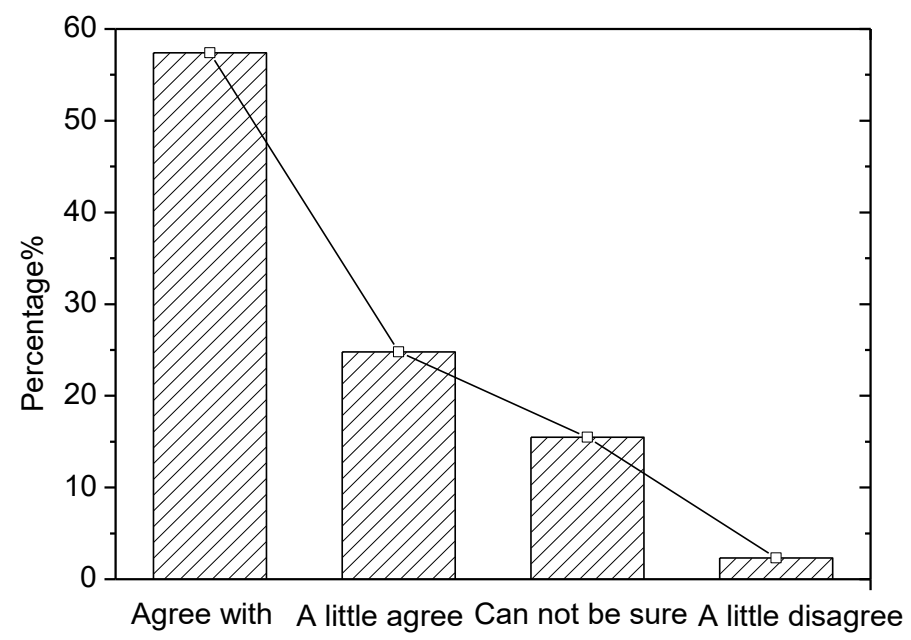

Fig. 3. Statistics on whether students think the teachers have taken SRI ability as the primary cultivation goal

\section{Students' satisfaction with scientific research conditions}

Common thoughts generally believe that only science and engineering majors need to carry out SRI activities, and people tend to pay more attention to the SRI of science and engineering majors, however, in the fact, SRI is equally important for art and sports majors. Figure 4 shows the survey results of sport majors' satisfaction with scientific research conditions. According to the figure, $37.1 \%$ of the students believe that the school does not attach importance to the SRI of sports major, $27.3 \%$ of them think the sports facilities in the school is in shortage, and $20.1 \%$ of them think the 
schools' input in the SRI of sports major is insufficient. The survey results show that, students are not satisfied with the school's scientific research conditions.

\section{Students' interest in SRI}

Interest is the best teacher. Only the real interest in SRI can drive students to learn and research on their initiative. Figure 5 shows the survey results of sports majors' interest in SRI. According to the figure, $56.8 \%$ of students express a general-level interest in SRI, $6.5 \%$ and $2.5 \%$ of them have little interest in SRI or do not interest in SRI at all; students who are interested in or very interested in SRI only accounted for $18.7 \%$ and $15.5 \%$, respectively.

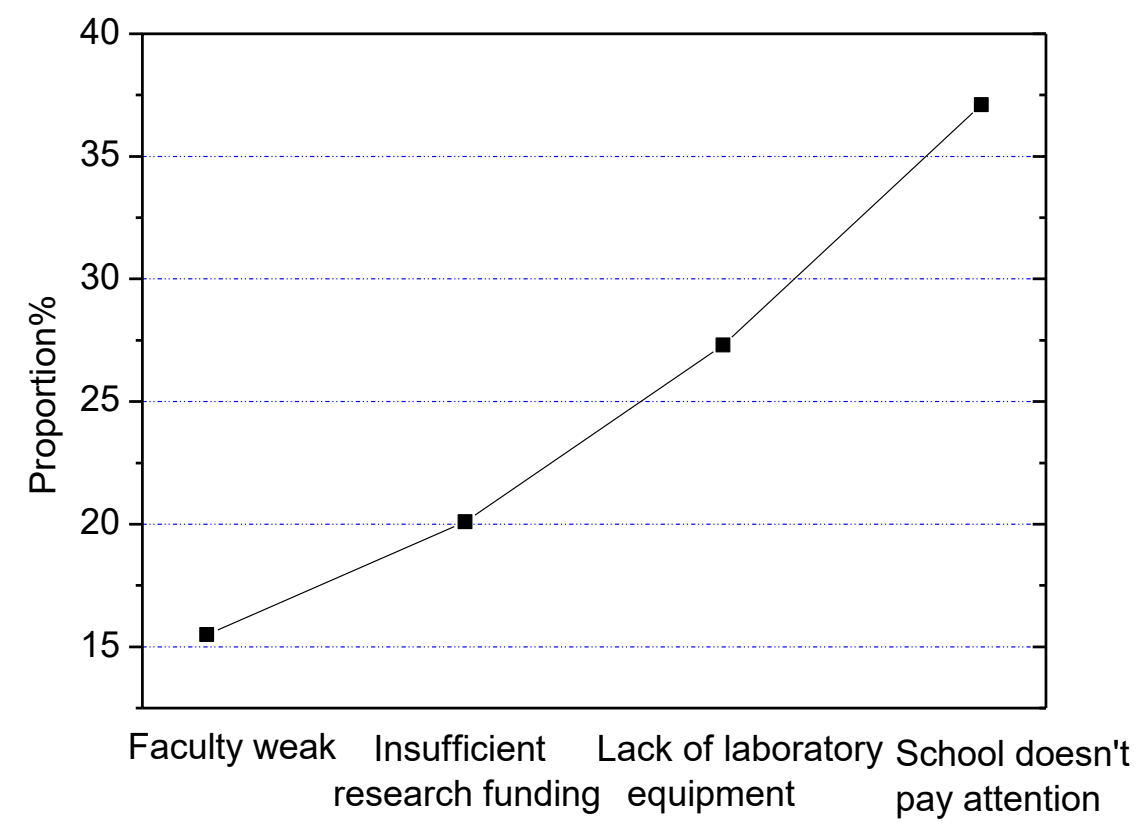

Fig. 4. Sports majors' satisfaction with the school's scientific research conditions 


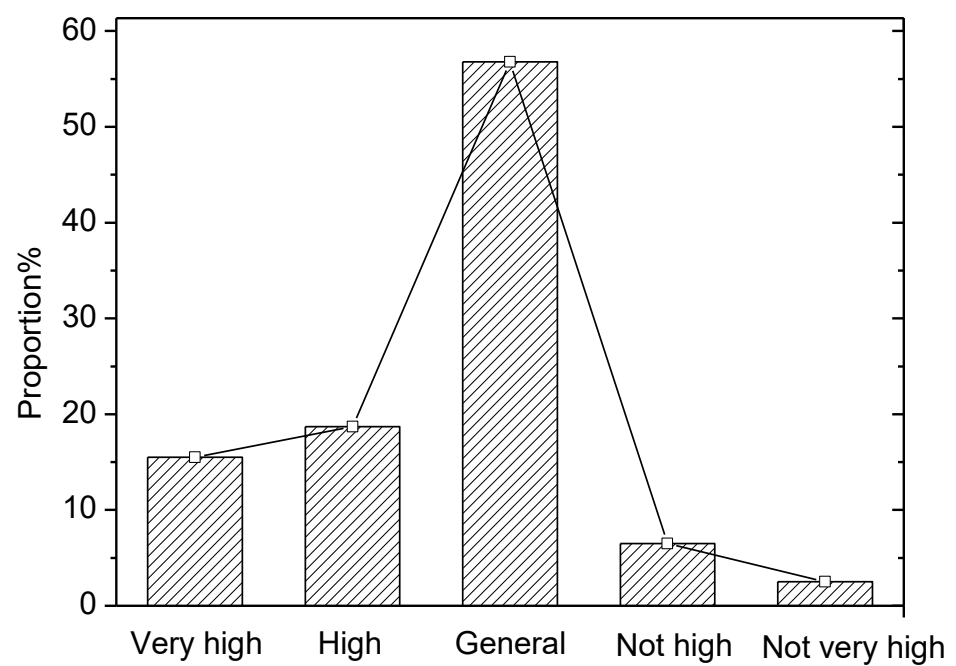

Fig. 5. Sports majors' interests in SRI

\section{SRI ability of teachers}

Teachers' SRI ability can affect students' SRI ability to a certain extent, this is because only teachers with good SRI ability can give targeted instructions to students [13]. Table 3 shows the statistics of the teacher paper publication and research program participation. According to the table, $71.43 \%$ of respondent teachers have published 10-15 papers in the recent five years, the number of papers is in an average level; $82.14 \%$ of respondent teachers have published 1-2 papers in core journals in the recent five years, the number of papers is relatively low. For the research programs these respondent teachers have participated, provincial-level and department-level programs accounted for a great proportion, and further survey results show that the awards received by these teachers are mostly provincial-level and department-level awards for research papers. Figure 6 shows the statistics of awards received by respondent teachers for their published papers, and these data indicate that these sports teachers' SRI ability is not outstanding.

Table 3. Statistics of teacher paper publication and research program participation

\begin{tabular}{|l|c|c|c|c|}
\hline \multicolumn{1}{|c|}{ Number of published papers } & $\mathbf{1 0}<$ & $\mathbf{1 0 - 1 5}$ & $\mathbf{1 6 - 2 0}$ & $\mathbf{2}$ \\
\hline $\begin{array}{l}\text { Number of teachers } \\
\text { (proportion) }\end{array}$ & $\begin{array}{c}3 \\
10.71 \%\end{array}$ & $\begin{array}{c}20 \\
71.43 \%\end{array}$ & $\begin{array}{c}4 \\
14.29 \%\end{array}$ & $\begin{array}{c}1 \\
3.57 \%\end{array}$ \\
\hline $\begin{array}{l}\text { Number of papers published by core } \\
\text { journals }\end{array}$ & 0 & $1-2$ & $3-4$ & $\geq 5$ \\
\hline $\begin{array}{l}\text { Number of teachers } \\
\text { (proportion) }\end{array}$ & $\begin{array}{c}1 \\
3.57 \%\end{array}$ & $\begin{array}{c}23 \\
82.14 \%\end{array}$ & $\begin{array}{c}3 \\
10.71 \%\end{array}$ & $\begin{array}{c}1 \\
3.57 \%\end{array}$ \\
\hline Research program level & National level & Provincial & Departmental & School level \\
\hline $\begin{array}{l}\text { Number of teachers } \\
\text { (proportion) }\end{array}$ & $\begin{array}{c}2 \\
10.71 \%\end{array}$ & $\begin{array}{c}22 \\
78.57 \%\end{array}$ & $\begin{array}{c}18 \\
6.29 \%\end{array}$ & $32.14 \%$ \\
\hline
\end{tabular}




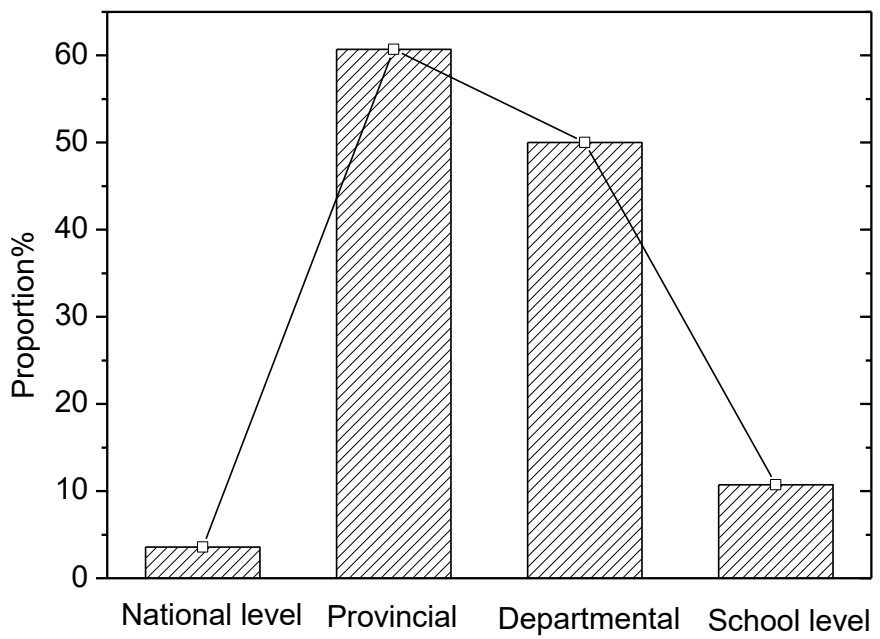

Fig. 6. Statistics on awards received by respondent teachers for their published papers

\subsection{Cultivation strategies for the SRI ability of sports majors}

According to above survey results and analysis, we can see that the SRI ability of sports majors is relatively weak, and the sports teachers' SRI ability is average; the teachers' instruction and cultivation of students' SRI ability is not enough, and schools generally pay insufficient attention to the cultivation of sports majors' SRI ability, and they have not provided good conditions or environment for the cultivation of sports majors' SRI ability. In view of these problems, this paper proposes the following countermeasures, as summarized in Figure 7.

\section{Develop sports majors' interest in SRI}

In the process of daily classroom teaching, and instructing and communicating with students, sports teachers can use heuristic Q\&A method to encourage students to think actively, trigger their thirst for knowledge, and inspire their exploring spirit, so that the students could have more interests in SRI, and their SRI ability and innovative thinking could be strengthened.

2. Enhance the SRI ability of sports faculty and ensure enough instruction time

Teachers' SRI ability directly determines the cultivation of students' SRI ability. Sports teachers should make efforts to enhance their own SRI ability. However, teachers with good SRI ability do not necessarily mean that they are good at teaching students, therefore, it's suggested that the schools can hold seminars or symposiums for teachers to communicate and exchange with other teachers, so that they could have the opportunities to share experience or learn from other teachers about how to cultivate students' SRI ability, and constantly improve their teaching ability to cultivate sports majors' SRI ability. 
College students generally have to undertake the dual tasks of teaching and SRI; therefore, they have very limited time to communicate with students, and the available time is far from enough for teachers to give instructions to students' SRI ability, schools should appoint a specific time each week for the communication between teachers and students; to ensure effective communication, both teachers and students should keep a record of the communication content and the feelings and gains they have, and include these in the assessment of teachers and students.

\begin{tabular}{|l|l|}
\hline $\begin{array}{r}\text { Attach importance to the cultivation of college } \\
\text { students' interest in scientific research }\end{array}$ \\
\hline \begin{tabular}{|} 
Strengthen the construction of the teaching team \\
and ensure the guidance time
\end{tabular} \\
\hline \begin{tabular}{|} 
Research and innovation \\
ability training strategy
\end{tabular} & \begin{tabular}{|} 
Improve the curriculum system and teaching \\
evaluation system
\end{tabular} \\
\hline $\begin{array}{c}\text { Guide college students to participate in scientific } \\
\text { research and innovation practice activities }\end{array}$ \\
\hline \begin{tabular}{|l|} 
Improve the scientific research incentive system \\
\hline Strengthen the construction of scientific research \\
infrastructure
\end{tabular} \\
\hline
\end{tabular}

Fig. 7. Strategies for the cultivation of sports majors' SRI ability

3. Improve the curriculum system and the teaching evaluation system

In order to further enhance sports majors' interest in SRI, schools should give students more freedom to select professional courses and elective courses according to their own interests, set up some courses that can cultivate students' SRI ability, such as the academic report course, so that they could understand the basic norms of scientific research and get familiar with the basic process of SRI. Also, it's advised to open some interdisciplinary elective courses, which would not only be helpful to the cultivation of versatile talents, but also can inspire college students in SRI.

In the specific teaching process, teachers should replace the traditional teaching methods with more flexible teaching methods, mobilize students to participate in the classroom teaching activities, combine teaching activities with scientific research, learning and innovation, and transform the classroom teaching to SRI courses. Also, in terms of course assessment, the process evaluation of students' SRI ability, learning attitude, and learning process should be included in the assessment.

4. Guide students to participate in SRI practice

In daily teaching activities, SRI-related concepts should be instilled to students so that they could have a correct understanding of SRI, meanwhile, by holding various activities such as regular academic seminars, symposiums, patent knowledge lectures, 
and SRI competitions, we could create a good SRI environment for students, so as to encourage them to actively participate in SRI practice, and improve their SRI ability and awareness.

\section{Improve SRI incentive mechanism}

A sound SRI incentive mechanism is the basis for promoting the SRI activities of college students. Schools should formulate corresponding SRI incentive measures, for students who had academic papers or works published in various journals, or had invention patents, not only their publication-related expenses should be reimbursed, but also some rewards should be given to them, so that they can devote themselves to SRI activities with all their heart. Moreover, since students' SRI ability varies from person to person, different SRI incentive mechanisms should be formulated according to the actual situations of students in each school, different staged evaluation indicators should be designed for undergraduates and postgraduates of different grades, and they should be included in the assessment to promote all students to actively participate in SRI. At the same time, we could also encourage students to form research teams, affirm and reward the SRI achievements accomplished by student research teams, and stimulate students' interest and enthusiasm in SRI.

\section{Improve SRI infrastructure}

To better open up students' minds and promote their SRI ability, schools should strengthen the construction of basic SRI facilities, build information exchange platforms for students' SRI activities, set up SRI centers or bases for college students, and achieve SRI resource sharing among colleges and universities in a same region to facilities students' exchange and communication; moreover, schools should upgrade library resources in a timely manner so that students could get in touch with the latest professional knowledge, and they could have a better SRI environment.

\section{Conclusion}

The cultivation of sports majors' SRI ability is crucial to the development of sports talents and the sports major, this paper carried out a research on the cultivation of sports majors' SRI ability, and the specific conclusions are as follows:

1. Based on an analysis of the concept of SRI ability and its influencing factors, this paper proposed the structure of sports SRI ability, which provided a basis for the subsequent survey and strategic research on sports majors' SRI ability.

2. The survey results of college sports majors' SRI ability show that: sports majors' SRI ability is generally weak; sports teachers' SRI ability is average; the teachers' instruction and cultivation of students' SRI ability is not enough; schools generally pay insufficient attention to the cultivation of sports majors' SRI ability, and they have not provided good conditions or environment for the cultivation of sports majors' SRI ability. 
3. With an analysis of the influencing factors of SRI ability and a diagram of sports SRI ability structure as the basis, this paper combined with the survey results to propose strategies for improving college sports majors' SRI ability from the aspects of interest development, faculty building, and infrastructure construction, etc.

\section{Acknowledgement}

This work was supported by Basic research project of basic scientific research business expenses of provincial colleges and universities in Heilongjiang Province (No. KYYWF10236190135) and Heilongjiang Provincial Philosophy and Social Science Research Planning Annual Project (No. 18TYE567).

\section{References}

[1] Glover, J.A., Tramel, S. (1976). Comparative levels of creative ability among students with and without behavior problems. Psychological Reports, 38(3S): 1171-1174. https://doi.org/10.2466/pr0.1976.38.3c.1171

[2] Erbas, A.K., Bas, S. (2015). The contribution of personality traits, motivation, academic risk-taking and metacognition to the creative ability in mathematics. Creativity Research Journal, 27(4): 299-307. https://doi.org/10.1080/10400419.2015.1087235

[3] Beghetto, R.A. (2006). Creative self-efficacy: Correlates in middle and secondary students. Creativity Research Journal, 18(4): 447-457. https://doi.org/10.1207/s15326934crj1804_4

[4] Desbordes, M. (2002). Empirical analysis of the innovation phenomena in the sports equipment industry. Technology Analysis \& Strategic Management, 14(4): 481-498. https://doi.org/10.1080/0953732022000028764

[5] González-Serrano, M.H., Añó Sanz, V., González-García, R.J. (2020). Sustainable sport entrepreneurship and innovation: a bibliometric analysis of this emerging field of research. Sustainability, 12(12): 5209. https://doi.org/10.3390/su12125209

[6] Hyysalo, S. (2010). User innovation and everyday practices: micro-innovation in sports industry development. R \& D Management, 39(3): 247-258. https://doi.org/10.1111 j.1467-9310.2009.00558.x

[7] Sinelnikov, O.A., Hastie, P.A. (2010). Students' autobiographical memory of participation in multiple sport education seasons. Journal of Teaching in Physical Education, 29(2): 167183. https://doi.org/10.1123/jtpe.29.2.167

[8] Forte, A. (2013). The moral reasoning of sports management students in the united states and Italy. Journal of International Education Research, 9(2): 177-198. https://doi.org/10. 19030/jier.v9i2.7723

[9] Billat, L.V. (2001). Interval training for performance: a scientific and empirical practice: special recommendations for middle- and long-distance running. part ii: anaerobic interval training. Sports Medicine, 31(2): 75-90. https://doi.org/10.2165/00007256-200131020$\underline{00001}$

[10] Cicirelli, V.G. (1969). University supervisors\" creative ability and their appraisal of student teachersl" classroom performance: an exploratory study. Journal of Educational Research, 62(8): 375-381. https://doi.org/10.1080/00220671.1969.10883870 
[11] Kansal, D.K. (2010). A critical study of sports talent selection and promotion of sports participation, at young age. British Journal of Sports Medicine, 44: i65-i66. https://doi.org/10.1136/bjsm.2010.078725.219

[12] Lees, A. (2003). Science and the major racket sports: a review. Journal of Sports Sciences, 21(9), 707-732. https://doi.org/10.1080/0264041031000140275

[13] Caza, A. (2000). Context receptivity: innovation in an amateur sport organization. Journal of Sport Management, 14(3): 227-242. https://doi.org/10.1123/jsm.14.3.227

\section{$7 \quad$ Authors}

Min Tang was born in Songyuan, Jilin, China, in 1982. She received the master degree from Shenyang sport University, P.R. China. Now, she works in School of Sports, Suihua University, His research interest is athletic training. E-mail: gwz102424@163.com

Dancheng Wei was born in Jixi, Heilongjiang, China, in 1998. He received the bachelor's degree from Suihua University, P.R. China. Now, he studies in School of Sports, Suihua University, His research interest is athletic training. E-mail: shxyjwc@126.com

Article submitted 2021-01-10. Resubmitted 2021-02-14. Final acceptance 2021-02-16. Final version published as submitted by the authors. 